\title{
Evaluative Study on Effectiveness of Maternal and Child Health Care Participatory Training Program among Staff Nurses, Auxiliary Nurse Midwives and Lady Health Visitors
}

\author{
Anitha C Rao, Prasannakumar Shetty
}

\begin{abstract}
Objectives: The objectives of the study are to: (i) Determine the learning needs of staff nurses, auxiliary nurse mid wives and lady health visitors on maternal and child health care. (ii) Determine the level of knowledge and selected maternal and child health care practices of staff nurses, auxiliary nurse midwives and lady health visitors on maternal and child health care before and after the implementation of the educational intervention program. (iii) E valuate the effectiveness of maternal and child health educational intervention program.
\end{abstract}

\begin{abstract}
Materials and methods: This evaluative study at selected health centers of Udupi district in India enrolled 50 staff nurses, auxiliary nurse midwives and lady health visitors who were currently employed.
\end{abstract}

Results: Major findings of the study were: There was a significant improvement $(p<0.05)$ in the performance skill related to antenatal, postnatal and newborn.

Conclusion: The training was effective in improving the overall performance of the workers. However, repeated in-service training is necessary in maintaining the levels of improvement.

Keywords: Maternal and child health care training program, Staff nurses, Auxiliary nurse midwives and lady health visitors.

How to cite this article: Rao AC, Shetty P. Evaluative Study on E ffectiveness of Maternal and Child Health Care Participatory Training P rogram among Staff Nurses, Auxiliary Nurse Midwives and Lady Health Visitors. J South Asian Feder Obst Gynae 2012;4(2):120-122.

\section{Source of support: $\mathrm{Nil}$}

Conflict of interest: None declared

\section{INTRODUCTION}

Nearly 529,000 women mostly in developing countries die from chil dbearing related causes each year. ${ }^{1} \mathrm{~A}$ I most $80 \%$ of maternal deaths are due to direct obstetric causes including hemorrhage, infection, complications of unsafe abortion, eclampsia and obstructed labor. For every woman who dies, many more women suffer from disease and disability at the height of their productivity and family responsibility. ${ }^{2}$ In addition to this, nearly 4 million newborns die before their first month of life from infection, asphyxia and trauma, complications of prematurity and low birth weight and congenital anomalies. ${ }^{3}$

A mother's health profoundly affects the health and wellbeing of her child. Over the last two decades, many other health indicators have improved; maternal mortality rates and ratios have remained stagnant. The causes are rooted in the absence of high level commitment in protecting women's heal th and in the powerlessness of women, as there is a clear connection between the low status of women and the risk of maternal illness and death. It is more likely in countries that give little priority to heal th services for women like maternal care and in certain cultures where maternal illness, suffering and death are viewed as natural and inevitable. ${ }^{4}$

The maternal health improvement requires a continuum services particularly, referral capacity for the management of complications. This requires staff trained in midwifery skills at various levels of the health system, and well-functioning facilities accessible to clients and equipped with essential obstetric drugs and supplies. ${ }^{5}$

Safe motherhood interventions can strengthen the performance of the health system. The effectiveness of maternal health services is often hampered by organizational and institutional constraints. Improving access to good-quality maternal health care remains a challenge in many countries because it requires a functioning primary heal th care system in the community and a referral system to a heal th facility capable of providing emergency obstetric care. Safe motherhood interventions designed to integrate these different sectors of the health service can thus, bring about improvements that more broadly affect the health system. ${ }^{6}$

The service providers like the staff nurses, auxiliary nurse midwives and lady health visitors who work as a team are 'facilitators' for community activities. These groups of service providers collectively can set realistic goals and develop plans for tackling problems confining to maternal and child health. In addition to providing basic services, a supportive system in the form of appropriate training and supervision of these providers at various levels using participatory training program will help in the implementation of appropriate activities, as well as monitoring and evaluating the community-based program. Thus, this study attempts to evaluate the effectiveness of maternal and child heal th care participatory training program among staff nurses tow ard training of auxiliary nurse midwives and lady health visitors in selected heal th care centers.

\section{MATERIALS AND METHODS}

The study was conducted at health care centers of $U$ dupi district, Karnataka. An evaluative approach was used in the present study. The population comprised of staff nurses, auxiliary nurse midwives and lady heal th visitors who were currently working at the selected health centers were drawn by convenient sampling technique. The sample size of 50 was considered for the study. A well-designed precoded, pretested schedule in the form of multiple choice was administered in the form of written evaluation which was used to test knowledge and a performance evaluation was used to test skills. The pretest was conducted 
on day one and on the same day intervention was implemented. A fter analyzing the baseline knowledge and skill status of the staff nurses, auxiliary nurse midwives and lady heal th visitors, a pretested self-learning educational material along with different method of teachings like role play, demonstration, simulation, discussions was introduced. Evaluation was done at 1 week interval after the intervention was introduced for final assessment. Their cognitive and psychomotor domains were assessed by a scoring method. A score of one was all otted to each correct answer and zero was given when the answer was totally wrong.

\section{RESULTS}

M ajority of staff nurses 5 (50\%) had in-service education in the past month, $54.83 \%$ of the ANM had never received inservice training, however $80 \%$ of the lady health visitors also reported of not undergoing any form of in-service training on $\mathrm{MCH}$ care during the past 1 year. Hundred percent of the staff nurse, ANM and lady health visitors agreed that training in $\mathrm{MCH}$ care is important to prevent maternal and neonatal mortality and morbidity. M ajority of staff nurses 7 (70\%), 100\% of ANM and $100 \%$ of the lady health visitors selected demonstration as their preferred method of teaching. $M$ ajority of staff nurses $6(60 \%)$ needed training on antenatal care. Overall $91.4 \%$ of ANM and $100 \%$ of the lady health visitors needed training on preventive care during the postnatal period.

In relation to age, majority $60 \%$ of the staff nurses, $82.9 \%$ of A N M s and $80 \%$ of the lady health visitors were aged between 25 and 35 years. Fourty percent of staff nurses, $91.4 \%$ of the A N M s and $100 \%$ of lady heal th visitors had more than 5 years of experience.

The mean knowledge score in the area of antenatal care for staff nurses was 4.7 (SD, 1.25) with a range of 3 to 7 , reflecting the high knowledge levels of those who attended. A fter training the mean knowledge score was 7.9 (SD, 1.911), pretest evaluation showed that, there was a difference in the depth of knowledge regarding antenatal care between subjects. This difference was statistically significant $(p<0.05)$. Pre- and posttest evaluation showed that, there was a statistically significant improvement in the percentage of auxiliary nurse midwives who gained knowledge regarding referral service, if there were antenatal complications, and regarding the importance of immunization during pregnancy. The improvement in the percentage of previously trained lady health visitors who gained knowledge regarding antenatal care was not statistically significant as they were aware of antenatal care.

Following the intervention, auxiliary nurse midwives had higher knowledge for intranatal care than the staff nurses and lady health visitors $19.6 \pm 1.24$ vs $17.4 \pm 1.95,19.2 \pm 1$.

Comparisons were made for those samples who completed both pre- and postintervention questionnaires. There were significant differences between the groups before and after training, particularly in postnatal and newborn care knowledge, with lady heal th visitors having the low est scores and auxiliary nurse midwife the highest $(p<0.001)$. The mean knowledge scores for staff nurses increased after training but the increase was not statistically significant, probably because they started at quite a high level.

There was a significant improvement in the assessment of antenatal examination by the staff nurses (from 11.9 to 23.50), A N M s (from 5.88 to 13.17) and lady heal th visitors (from 5.80 to 28.40) following the intervention.

The mean pretest skill scores for conduction of delivery (from $8.9 \pm 1.59$ to $17.4 \pm 1.50$ ) for staff nurses, ANM s (from $9.08 \pm 0.919$ to $17.72 \pm 1.27$ ) and lady health visitors (from $9.00 \pm 1.58$ to $17.60 \pm 0.894$ ) increased significantly in the post-intervention.

There was a significant improvement in preparing the items needed for neonatal resuscitation.

The assessment of newborn at birth improved in the intervention group at a significant level following the intervention.

High significant difference was observed between the preintervention and postintervention knowledge scores in intranatal care $(p<0.05)$ on applying one-way ANOVA indicating the effectiveness of teaching in improving the knowledge.

However, one-way ANOVA test showed no significant difference in the mean skill scores in the area of conduction of delivery.

\section{DISCUSSION}

Training programs can be view ed as a key strategy in promotion of heal th care services. The findings of the present study suggest that the implementation of a comprehensive training program on $\mathrm{M} \mathrm{CH}$ care can be followed by a significant improvement in the practices of immediate newborn assessment in the labor room. The training may possibly have an effect in reducing undesirable health events. This finding is in line with a study conducted by Senarath $U$ et al ${ }^{7}$ a comprehensive 4-day training program of ENC for maternity unit heal th care providers which had significant improvement in the ENC practices during delivery and postnatal period in the hospital setting. The present study contained more interactive methods in the training, such as demonstrations, hands-on training and practical assignments. According to Davis et al interactive training sessions that enhance participant activity and provide the opportunity to practice skills can effect change in professional practice. $^{8}$

\section{CONCLUSION}

The findings of the study suggests improvements in scores between the pretraining period and posttraining period demonstrated that the training in $\mathrm{MCH}$ care significantly increased scores on evaluations of knowledge and skills in midwives despite their earlier advanced formal education and many years of experience. $M$ aintaining midwives' knowledge and skills through retraining or reinforcement could be pivotal to maintaining the high levels of $\mathrm{MCH}$ care skills in midwives required to prevent maternal and infant mortality. However, the role of repeated training through on the spot demonstrations has to be emphasized. Therefore, reorientations of their training and frequent in-service refresher courses are suggested because training in any service delivery service program is significant. 


\section{REFERENCES}

1. W orld B ank. M aternal M ortality [Public Health at a Glance] 2006. A vailable from: http://www.worldbank.org, accessed 4/5/2007.

2. A bouZahr C, Wardlaw T (2003). M aternal M ortality in 2000: Estimates developed by W HO, U NICEF and UNFPA. Geneva: WHO. A vailable at: http://www.who.int/reproductivehealth/ publications/maternal_mortality_2000/mme.pdf, (accessed on 10 October 2010).

3. Lawn JE, Cousens SN, Zupan J. Four million neonatal deaths: When? Where? Why? Neonatal Series Paper 1. Lancet 2005;365(9462):891-900.

4. The W orld Bank. Safe motherhood and the W orld Bank: L essons from 10 years of experience. W ashington DC: The W orld Bank; J une 1999.

5. UNICEF. Programming for safe motherhood. New York: UNICEF/H ealth Section/Programme Division 1999.

6. A bas $M$, B aingana F, B roadhead J, I acoponi E, V anderpyl J . Common mental disorders and primary health care: Current practice in low-income countries. Harv Rev Psychiatry 2003; 11:166-73.
7. Senarath U, Fernando DN, R odrigo I. Effect of training for care providers on practice of essential newborn care in Hospitals in Sri Lanka. JOGN N 2007;36(6):531-41.

8. Davis D, O' Brien M AT, F reemantle N, W olf FM, M azmanian $P$, Taylor-V aisey A. Impact of formal continuing medical education: Do conferences, workshops, rounds, and other traditional continuing education activities change physician behavior or health care outcomes? J Am Med Assoc 1999;282:867-74.

\section{ABOUT THE AUTHORS}

\section{Anitha C Rao (Corresponding Author)}

Associate Professor, Department of Obstetrics and Gynecology Canara C ollege of N ursing, Prafull Enclave, Halady R oad, K oteshwar PO B ox: 576222, K undapur, Udupi, K arnataka, India, Phone: 09845352632, e-mail: anitha852002@yahoo.co.in

\section{Prasannakumar Shetty}

Professor, Department of Obstetrics and Gynecology, KS Hegde M edical College, M angalore, Karnataka, India 